\title{
IMÁGENES EN LA HISTORIA DE LA ENSEÑANZA: LA LÁMINA ESCOLAR
}

\author{
DANIEL FELDMAN ${ }^{*}$
}

RESUMEN: El trabajo propone algunas reflexiones sobre el papel de las imágenes en la historia de la enseñanza escolar. Se procura analizar esta cuestión entrelazando dos puntos de vista. En primer lugar, algunas respuestas que fueron provistas, principalmente durante el siglo XIX e inicios del siglo XX, a la pregunta ¿qué papel juega la representación del mundo, de las cosas, en el conocimiento y cómo la pedagogía creyó que debe proceder la enseñanza escolar para promover el conocimiento? En segundo lugar, la descripción de algunos rasgos que describen la evolución del uso de imágenes en las escuelas públicas argentinas. Los dos puntos de vista se vinculan para analizar los cambios en el uso de la imagen figurativa y fija en la práctica escolar. Se propone que el cambio principal está ligado con el paso en el uso de las imágenes como base de conocimiento mediante la intuición sensible, al uso de las imágenes como apoyo informativo, recurso de organización o expresión del trabajo de los alumnos. Se utiliza esta reflexión sobre el cambio en el uso de las imágenes escolares para considerarlo como caso de una hipótesis de orden más general sobre el desarrollo del currículum y de los patrones de formación en Argentina.

Palabras claves: Enseñanza escolar. Currículum. Historia de la escuela.

\section{IMAGES IN THE SCHOOL TEACHING HISTORY: THE USE OF FIGURATIVE AND FIX IMAGES}

ABSTRACT: This work aims at discussing the role of image in the school teaching history, interweaving points of view. First of all, it focuses the ways representation and knowledge were conceived of in the pedagogical studies developed during the XIX ${ }^{\text {th }}$ and $\mathrm{XX}^{\text {th }}$ centuries. It also accounts for some facts related to the evolution of the use of image in the Argentinean public schools. As far as the changes in the use of figurative and fix images in school practices are concerned,

* Doutor e professor da Universidade de Buenos Aires. E-mail: dfeldman@filo.uba.ar

Educ. Soc., Campinas, vol. 25, n. 86, p. 75-101, abril 2004

Disponível em <http://www.cedes.unicamp.br> 
Imágenes en la historia de la enseñanza: La lámina escolar

it concludes that the main shift was in the use of image, from a knowledge basis through sensitive intuition into an information support as well as a resource for the students' works. This result is referred to curriculum development and educational patterns in Argentina.

Key words: Learning process. Curriculum. School history.

Historias de imágenes

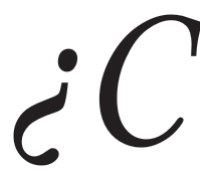

uál ha sido el uso de las imágenes en la historia de la enseñanza escolar? La pregunta puede responderse en dos campos: en el campo de las ideas pedagógicas; o en el de las prácticas de os cientos de miles de escuelas donde la ense-

ñanza se impartió día a día en los últimos, digamos, 350 años. Porque si se toma como punto de inicio la aparición del Orbis Sensualium Pictus de Comenio, a mediados del siglo XVII, se trata de una larga historia. Este "había una vez" se sitúa en el momento en que el uso de imágenes se reúne con una concepción metódica de la enseñanza y con el desarrollo de los dispositivos escolares.

Cuando se analiza desde el campo de las ideas pedagógicas la historia del uso de las imágenes, aparecen, inmediatamente, respuestas a dos preguntas: ¿Qué papel juega la representación del mundo, de las cosas, en el conocimiento? ¿Cómo la pedagogía creyó que debe proceder para promover el conocimiento, "el recto camino a la verdad"? Ensayaré sintetizar algunas de esas respuestas - fundamentalmente las que fueron provistas durante el siglo XIX e inicios del siglo $\mathrm{XX}-\mathrm{y}$ de su relación con la escolarización. Ese será, posiblemente, el principal punto de apoyo de este trabajo.

Ahora, si se toma en consideración el campo de las prácticas pedagógicas en los sistemas escolares, la cuestión es más difícil de abordar, simplemente por la dificultad de reconstruir las prácticas cotidianas pasadas de las escuelas. Pero hay indicios que pueden utilizarse. Por ello me referiré, de un modo muy general en este trabajo, a algunos rasgos que, a mi juicio, describen la evolución del uso de imágenes en las escuelas públicas de mi país. No dejaré, para ello, de utilizar el conocimiento que adquirí por mi experiencia. Procuraré, también, vincular estos rasgos con ideas pedagógicas vigentes en cada momento. 
Este texto tiene algo de personal. Si se trata del papel de las imágenes en la enseñanza escolar, en varios sentidos, me siento parte de la historia. En una primera etapa, como alumno de escuelas primarias públicas nacionales hacia finales de los años 1950. En una segunda etapa como aprendiz de maestro en la Escuela Normal Nacional no 2 entre 1963 y 1967. La tercera, como maestro de escuelas públicas en la ciudad de Buenos Aires durante la década de 1970. La cuarta, como alguien dedicado a la didáctica. Empezaré por el final para contarla.

Soy ahora un especialista en didáctica y currículum. Un miembro de la didáctica académica, si algo así no es un oxímoron. Una didáctica producida, en gran medida, por grupos de investigadores y especialistas en ámbitos universitarios. Estos grupos procuran una extensión creciente de sus propuestas a nuevos públicos, mientras atiendan a sus comunidades académicas de pertenencia. Como miembro de esa didáctica no es demasiado fácil sentirse parte de la tradición. En buena medida, porque esa memoria se ha enflaquecido en el último tiempo. Será, quizás, porque esa comunidad sufrió un salto teórico, ideológico y valorativo que podríamos llamar, para usar un término excesivamente general, la hegemonía constructivista. El corte que producen las nuevas concepciones educativas sobre el niño y su actividad, reconoce sus orígenes en la Escuela Nueva. Pero no todas las tendencias dentro del movimiento de la Escuela Nueva promovían, desde el punto de vista que nos ocupará aquí, la misma ruptura con el pasado. Son la difusión, extensión y aceptación pedagógica de teorías como la psicogénesis piagetiana las que acentuarán esa discontinuidad. Hans Aebli, un importante miembro de esa escuela de pensamiento en el terreno educativo, denominaba a ese pasado como "la psicología y la epistemología sensual empirista" (Aebli, 1958, p. 13). El sensual empirismo tuvo su impulso principal en educación a inicios del siglo XIX, con la pedagogía intuitiva de Pestalozzi. Diré, anticipadamente, que en su seno se desarrolla la parte principal de la historia de las imágenes en la enseñanza.

Como académico, pertenezco a una didáctica donde el uso de imágenes fijas (modelos, láminas, dibujos, presentaciones gráficas) modificó sustancialmente su valor en las últimas décadas. Consultando algunos importantes manuales actuales no he podido encontrar en ellos nada que haga referencia especial al uso de las imágenes o de los 
Imágenes en la historia de la enseñanza: La lámina escolar

objetos como parte de la enseñanza. Los 23 "modelos de enseñanza" compilados y organizados por Joyce, Weil y Calhoun (2002) incorporan poco al respecto (algo puede hallarse sobre el uso de imágenes cómo recursos auxiliares en los modelos de memorización). Tampoco pueden hallarse mayores referencias en las 7 "estrategias docentes" que exponen Eggen y Kauchak (2000) para "la enseñanza de contenidos y desarrollo de las habilidades de pensamiento". No creo que sea por exceso de racionalismo o intelectualismo. Hay estrategias dirigidas al desarrollo de la creatividad, la elevación de la autoestima o la clarificación de valores. Incluso, la enseñanza se ve atravesada por nuevas formas de concebirlas ligadas a la imaginación y el relato. Puede verse, como ejemplo, la compilación de McEwan y Egan (1998) La narrativa en la enseñanza, el aprendizaje y la investigación. También se puede tener en cuenta la insistente, y bastante pionera, prédica de Jerome Bruner para rescatar el valor de la imaginación y el pensamiento narrativo. ${ }^{1}$ Pero el uso de imágenes no tiene ya un lugar estructural en la manera de conducir la enseñanza. Y me refiero, aquí, al uso de imágenes figurativas en la enseñanza básica y no a los crecientes reclamos de educación para la imagen. También estoy dejando de lado el uso de imágenes en los primeros años escolares, ligados a la educación inicial o al aprendizaje de la lecto escritura.

Algo sucedió, aparte del correr de los años, porque mi escuela, $y$, probablemente, la de otros que hayan pasado los 40 años de edad, era una escuela de láminas, de modelos de cera, de pizarrón y tiza de colores, de vitrinas.

Quisiera, entonces, comenzar mi reflexión sobre el tema con una imagen. Pero no la presentaré a su captación sensorial visual. Porque yo tampoco tengo presente el objeto. Lo evocaré, entonces. Espero que, aún así, pueda ser intuitivamente aprehendido.

Las salas de clase de mi niñez estaban pobladas de láminas que colgaban de las paredes. Algunas seguían el curso de las estaciones. El otoño, por ejemplo, era el cuaderno con papel azul araña, el papel secante fijado con una cinta y el ya asentado ritmo de trabajo en los dobles pupitres de madera. El otoño eran los impermeables de hule con capucha y las botas de goma. Pero el otoño era algo más: eran las láminas del otoño. En esos dibujos de editoriales educativas fijados en la pared, se veía el cruce de calles con las hojas revoloteando, las 
personas con el paso apresurado. Las líneas marcando el viento. El otoño no era solo una estación que enfriaba los cuerpos y las almas en esos atardeceres cada vez más tempranos y melancólicos. El otoño era un epítome fijo, escolar, en un rectángulo de nuestra sala. También estaba la lámina de los servidores públicos, todos decididos a transitar y ejercer su tarea a la misma hora, en la misma calle de un barrio de cualquier lugar. O la de la producción ganadera de la $\mathrm{Ar}$ gentina: todas esas vacas Shorton, Holando Argentina y Heresford, pisando los rectos límites geográficos de las extensas provincias de mi país. Podía uno ver, incluso, todas las flores y aves nacionales juntas en una extraña conjunción que ningún fenómeno natural podría jamás producir. $\mathrm{O}$ ese cuerpo mecánico, cuerpo fábrica mostrando el proceso de la alimentación con ruedas, cintas y poleas muy distantes de los procesos metabólicos (seguro, difíciles de dibujar). También figuraba, claro, la historia de la patria. Belgrano escribiendo entre recuerdos - dibujados ellos también - de bibliotecas, banderas y batallas. Y San Martín planificando, sentado sobre la cureña de un cañón (cuando no cabalgaba infatigable sobre su caballo blanco cruzando el Ande o atacaba, recio, en San Lorenzo). Y Sarmiento... Sarmiento, padre del aula, infatigable planificando cultivos, redactando un periódico, testimoniando Caseros, fundando y construyendo una escuela y besando a su amada madre anciana junto al telar, bajo la umbría parra de su San Juan natal. Todo ello, desplegado frente a nuestros ojos en un mismo instante revelador que reunía hechos, épocas, acciones en un solo haz abierto a la percepción, porque la Historia debía ser, literalmente, observada.

Ahora puedo precisar la idea que esbocé anteriormente. Dije que algo cambió en las escuelas. El cambio a que me refiero consiste en que el uso de la imagen - la imagen fija, figurativa - disminuyó progresivamente y perdió su importancia en la prescripción didáctica. Sigue teniendo un papel en las salas de clase, como "marcadora" de temas, eventos y acontecimientos, resultado de búsquedas de información o remedo de la impronta gráfica fija en las calles de la ciudad. También tiene un papel importante como expresión del trabajo de los alumnos. Pero ya no es un elemento para la apreciación sensible, para brindar la base del conocimiento. Este cambio tuvo un ritmo desparejo. Intuyo que mis salas de clase (en una modesta escuela 
Imágenes en la historia de la enseñanza: La lámina escolar

de un barrio de clase media baja) se parecían más a las de mis padres que a las que transité como maestro en los tempranos años 1970. Creo que mi propia formación como docente y el inicio de mi ejercicio transcurrieron en ese momento que haría que las cosas ya no se vieran igual. Este trabajo propone algunas reflexiones sobre ese cambio. No creo decir nada que sobre el asunto no se sepa. Quizás solo quiera reponerlo o darle un lugar en nuestra reflexión actual. También aproveché esta reflexión sobre el uso de imágenes en la enseñanza escolar para considerarlo como caso de una hipótesis de orden más general sobre el desarrollo del currículum y de los patrones de formación en Argentina.

\section{De Pestalozzi a Decroly}

Cuando evoco las ilustradas salas de clase de mi infancia como alumno de escuela primaria, recuerdo las innumerables tareas de ilustración que debía realizar. Si también pienso en las metodologías prácticas "de tiza de colores" que utilicé como maestro, no puedo dejar de reconocer que un hilo las une. Ese hilo es una concepción intuitivista. La que Aebli (1958) identificaba con la "pedagogía tradicional". Yo era heredero de la tradición que había tallado el desarrollo del sistema educativo en mi país y otros.

La práctica pedagógica propia de los sistemas nacionales de educación en nuestros países se organizó bajo las consignas de educación moderna, racional, objetiva e intuitiva. Los reformadores, que en siglo XIX promovieron la expansión de las escuelas y el avance de la instrucción masiva, recurrían a alguna teoría de las facultades de la mente y de su desarrollo armónico, mantenían una concepción tripartita del sujeto y de su formación ${ }^{2}$ y postulaban la primacía del entendimiento racional por sobre la memoria de palabras y la percepción sensible de la realidad como principio del aprendizaje. ${ }^{3}$

Esta nueva pedagogía se articuló sobre el principio de apreciación sensible como base del conocimiento. Una idea de la que ya había extraído consecuencias didácticas el trabajo de Comenio. Su artificio universal permitía enseñar con "facilidad, solidez y brevedad" las ciencias. La preceptiva era muy sencilla y surgía, como todo en el método comeniano, de la propia naturaleza. Dice así: 
3 - Cuatro son, por tanto, las condiciones que se deben procurar en el adolescente que desea investigar los secretos de las ciencias:

I Que tenga limpios los ojos del entendimiento.

II Que se le presenten los objetos.

III Que preste atención.

IV Que se le presenten unas cosas después de otras, con el debido método; así conocerá todas las cosas con certeza y expedición (...).

Es necesario que el conocimiento empiece por lo sentidos - cierto es que no hay nada en el entendimiento que antes no haya estado en el sentido (...). En segundo lugar, la verdad y la certeza de la ciencia no estriban más que en el testimonio de los sentidos (...). (Comenio, 1996, p. 123 y 124)

Comenio asienta, así, algunos principios claves para el futuro pedagógico de las presentaciones y representaciones de la realidad. El primero es de orden psicológico: no hay nada en el entendimiento que no haya estado previamente en el sentido. El segundo, epistemológico: la verdad y la certeza provienen del testimonio de los sentidos. El tercero, metodológico: percepción primero, explicación (análisis y síntesis), después. ${ }^{4}$ Una sencilla trinidad que recorrerá la pedagogía durante los siglos siguientes y participará en el proceso de alumbramiento de la escuela de masas. Deja también una regla: "Puede también, si en alguna ocasión falta el original, emplearse modelos o representaciones. Esto es modelos o imágenes preparadas para la enseñanza (...)" (Comenio, 1996, p. 126). Esta será una regla mayormente aceptada por todas las posiciones sensualistas. Tomaba sentido en el marco de la trinidad establecida.

Sin embargo, el funcionamiento de las dinámicas instruccionales y la convicción de que la experiencia directa no era posible en muchos casos darían con el tiempo muchísima importancia a las imágenes. De hecho el propio Comenio alcanzó celebridad universal por el Orbis Sensualium Pictus que, publicado en 1658, constituye el primer libro de texto ilustrado. Maravilloso en su sencillez, el Orbis Pictus propone una tecnología informativa que no fue superada hasta la llegada de los soportes informáticos. ¿Quién no recuerda esas figuras en las revistas escolares y enciclopedias juveniles donde, por ejemplo, un castillo medieval era atacado y defendido? Números en la escena constituían las referencias para que el curioso lector identificara, por ejemplo, el puente levadizo o las troneras, los arqueros, el arsenal 
Imágenes en la historia de la enseñanza: La lámina escolar

o las torres de asalto. Yo recorrí imágenes como esas. Comenio las propuso a los niños de su época hace casi 400 años. Sin ir más lejos, "El asedio a una Ciudad" es la imagen CXLIII."

Pero es Pestalozzi quien realizó la síntesis que tendría decisiva influencia en la estructuración de los sistemas de enseñanza. En Pestalozzi, la intuición de la naturaleza es el fundamento propio y verdadero de la instrucción humana, porque es el fundamento del conocimiento humano. Decía en Como enseña Gertrudis a sus hijos, publicado en 1802: “QQué es lo que realmente he hecho por la esencia de la instrucción humana?, hallo que he asentado firmemente el principio más alto y supremo de la instrucción al reconocer a la intuición como el fundamento absoluto de todo conocimiento" (Pestalozzi, 1936, p. 193). Su propuesta reservó un papel trascendente a las diferentes maneras de presentar el mundo a los niños. ${ }^{6}$

La instrucción tenía la misión de ordenar el mundo para dirigir adecuadamente la percepción de los niños y permitir la formación de los conceptos exactos y el desarrollo del intelecto. ${ }^{7}$ Esto era imprescindible porque la intuición no implica "ver" las cosas. Es, según Schmieder (1966, p. 75), una actividad interna, no una recepción. La intuición requiere una acción contemplativa y reflexiva que permita apreciar y ordenar los objetos según sus semejanzas y diferencias. Ayuda, guía y orden eran necesarios para que el niño pudiera entrar en el mundo y conocerlo sistemáticamente.

Para llevar a tus niños por el camino más corto al fin de la instrucción, a los conceptos exactos, debes poner primero a tu vista, con gran cuidado, en cada materia de conocimiento, aquellos objetos que presentan sensible y distintamente los rasgos característicos más esenciales de la materia a la que pertenecen y que, por ello, son singularmente adecuados para hacer visible la esencia de esa materia en vez de sus propiedades variables. (Pestalozzi, 1936, p. 222)

Para evitar que los niños se extravíen en las "propiedades variables" y no puedan pasar de las "intuiciones confusas a lo conceptos exactos” Pestalozzi proponía un procedimiento:

(...) son las series en las cuales se presentan ordenados a la intuición de los niños, desde los primeros puntos iniciales, todos los objetos de todas las 
materias de tu instrucción en tal forma que, si la impresión de la esencia de cada objeto comienza a elevarse desde sus primeras intuiciones sobre la impresión de sus accidentes, el niño aprende a subordinar desde esta primera impresión lo mudable del objeto a lo permanente. (Pestalozzi, 1936, p. 222)

Se trataba de que el niño ingrese al conocimiento del mundo, objeto por objeto. Las lecciones de cosas serían el instrumento pedagógico para este propósito.

La enseñanza objetiva procuraba la adquisición de nociones y el ejercicio y el desarrollo de las facultades intelectuales como percepción, memoria, razonamiento e imaginación. Por eso, la percepción de objetos se complementaba con cuidados sistemas de preguntas y respuestas del maestro que guiaban la percepción del niño desde las imágenes exteriores hacia las interiores y de allí a los juicios abstractos.

Como probablemente en toda pedagogía de profunda raíz filosófica, la obra de Pestalozzi fue difundida y aplicada de un modo tal que los preceptos de actividad quedaron, muchas veces, desgajados del fundamento metafísico que les daba sentido y unidad. Señala Bowen que Pestalozzi recurrió a una metáfora orgánica del desarrollo natural tomada de Rousseau. ${ }^{8}$ Pero el desarrollo de la enseñanza intuitiva que se expresaba en las lecciones de cosas, afirmadas a lo largo del siglo XIX, perdió el holismo organicista de la filosofía original. Esta es reemplazada por metáforas mecanicistas necesarias para la economía de trabajo y de tiempo. ${ }^{9}$

Es evidente que los jóvenes maestros-alumnos en formación no tendrían la más remota idea de la visión del mundo holista y científica en la que estaba fundada la lección de cosas. Las lecciones de cosas proliferaron, los niños eran estimulados a traer objetos a la clase (...) y no conseguían más que catálogos de rasgos extensos; el método prosperó a todo lo largo del siglo XIX mientras los objetos eran reducidos cada vez más a ilustraciones en gráficos murales. (Bowen, 1992, p. 426)

De todos modos, no debería afirmarse en cualquier caso que el uso de ilustraciones correspondiera, solamente, a una utilización degradada del método - aunque eso pudiera ser parte del asunto. La importancia de utilizar objetos naturales, ya señalada en Comenio, tenía sencillo y contundente fundamento en lograr el conocimiento 
Imágenes en la historia de la enseñanza: La lámina escolar

de las cosas por las cosas mismas. Pueden encontrarse fuertes recomendaciones en tal dirección. ${ }^{10}$ Sin embargo, el uso de láminas o de modelos que reemplazaran el natural podía ser aceptado. Por un lado, quedaban legitimamente exceptuadas todas las ocasiones en que el uso del natural no fuese posible por razones de practicidad o por el tipo de "cosa" que debiera ser conocida. Pero, por otro, existe la opinión de que, en el marco del intuitivismo, no había una diferencia cognitiva esencial en que el objeto fuese natural o artificial pues, en ambas formas, llegaba a la mente como representación. Obregón, Saldarriaga y Ospina proponen que

A ninguno de los contemporáneos ilustrados del maestro suizo se le hubiese ocurrido que podía haber diferencia, desde el punto de vista del conocimiento, entre la imagen dibujada en el papel y la imagen visual de la escalera real, por cuanto eran idénticas por naturaleza en tanto imágenes recibidas y representadas en signos. (1997, p. 23)

La importancia de las concepciones intuitivistas - y su correlato con el desarrollo de las facultades - se expresó en prescripciones metódicas y curriculares que adquirieron gran difusión. En Argentina, por ejemplo, distintos documentos oficializaron esta tendencia. Decía en 1888 el Plan de Estudios para las Escuelas Comunes del Consejo Nacional de Educación:

La enseñanza será intuitiva y práctica, empezando por la observación de objetos sensibles para elevarse después a la idea abstracta, a la comparación, generalización y raciocinio. La enseñanza que se de en las escuelas no solo debe asegurar los conocimientos útiles en la vida, sino también, y principalmente actuar sobre las facultades, desarrollando la inteligencia.

Esta adopción de la enseñanza intuitiva como pedagogía oficial, desde el inicio del sistema educativo estatal, continuaría por un largo período. De ese modo, en 1937 el Reglamento General para las Escuelas Públicas de la Provincia de Buenos Aires prescribía que “(...) La enseñanza será intuitiva y práctica, debiendo empezar siempre por la observación de los objetos familiares del niño. La enseñanza debe asegurar los conocimientos útiles de la vida, y especialmente, el desarrollo de las facultades".

A partir de su sistematización pedagógica a principios de 1800, con la obra de Pestalozzi, el principio de intuición fue parte 
protagónica en la escena didáctica. Con el correr del tiempo se comenzó a combinar con otras propuestas metódicas en un escenario de amalgamas múltiples. Las lecciones de cosas comenzaron a ser suplementadas con métodos deductivos ${ }^{11}$ o complementadas por otras escuelas de pensamiento que comenzaron a ganar aceptación pasada la mitad de siglo XIX. Tal es el caso de la pedagogía herbartiana difundida a través de la obra de Rein en la Universidad de Jena, a partir de $1885 .^{12}$

Como es sabido, la psicología de Herbart no alcanzó excesiva aceptación durante su vida. Los cuatro grados que organizaban la instrucción - claridad, asociación, sistema y método - no tuvieron mayor impacto en las prácticas escolares. Pero algunas décadas después su reelaboración hizo de esta concepción una de las más influyentes en la pedagogía y mantuvo cierta importancia en la formación de maestros hasta mediados del siglo XX. La cualidad de la psicología que la fundamentaba no variaba el supuesto asociacionista y perceptivo dominante hasta ese entonces. "Según Rein todo el proceso de aprendizaje completo muestra dos grados: el de apercepción y el de abstracción. El de apercepción suministra el materia visual de la representación, el de abstracción desarrolla con ese material los conceptos" (Gärtner, 1970, p. 135).

Para Rein era necesario que se pongan a disposición "representaciones existentes en la conciencia que deben acoger las representaciones nuevas". Por eso la apercepción (la claridad herbartiana) tiene un grado previo: la preparación; luego es la presentación de las nuevas representaciones; le sigue la asociación o comparación; la generalización o unión y, por último, la aplicación. La sistemática ofrecida resultó de gran atractivo porque su carácter estandarizado respondía mejor a los requerimientos de preparación de maestros en gran escala. También, quizás, por su capacidad de fusionar las propuestas prestigiosas existentes. Señala Bowen que

El herbartismo prosperaba, tras haber mostrado una considerable flexibilidad al incorporar dentro de sí mismo los rasgos estereotipados del pestalozzismo y del froebelismo, tales como las lecciones de cosas formalizadas, reducidas ahora a ilustraciones en libros de texto o en gráficos murales, y las 'ocupaciones' degradadas a ejercicios mecánicos de artesanía en plegado y corte de papel, (...). (Bowen, 1992, p. 444) 
Imágenes en la historia de la enseñanza: La lámina escolar

En sus distintas formas, el camino de las lecciones de cosas y el intuitivismo primarán en las escuelas en distintas alianzas metódicas, como las mencionadas en el párrafo anterior. Pero no será inmune a los avances de la Escuela Nueva y de algunos de sus principios. Principalmente los de actividad y globalización, inspirados en el trabajo de Decroly. Esto lleva, hacia los años 1930 a la difusión de propuestas basadas en los Centros de Interés. ${ }^{13} \mathrm{La}$ enseñanza objetiva incorporó principios del aprendizaje activo, pero estos avances no implicaron un corte con la concepción intuitivista.

En Decroly la observación es polisensorial - lo cual es un rasgo desde Comenio - y global. Esta concepción de globalidad lo aleja de los enfoques más bien discretos y unitarios de sus predecesores para quienes la separación entre objetos y fenómenos era necesaria para reforzar la "claridad" de las representaciones y evitar superposiciones indeseadas. Pero superada esta diferencia el enfoque se vuelve a aproximar. Luego de la captación global "se empieza por hacer ver el objeto de estudio y después se dirige el esfuerzo a explorar con los demás sentidos" (Not, 1983, p. 146). A la observación analítica del medio, sigue la asociación sintética de las representaciones. Entre el pragmatismo - con su énfasis en la actividad de resolución de problemas - y el intuitivismo se ubica la obra de Decroly que "tiende una especie de puente que lo vincula con los intuitivistas por la parte que concede al dato sensorial y a los pragmatistas (...)" (idem, p. 140). Estos vínculos pueden ayudar a explicar la permanencia del intuitivismo y de las estrategias asociadas con la formación de representaciones mediante los objetos o sus reemplazos. La percepción, la manipulación o el dibujo que la reemplazaba continuaron siendo una parte esencial de la experiencia escolar.

El principio de intuición postulado por Pestalozzi, y sus reelaboraciones en términos de las propuestas de Herbart y Decroly, resultaron de enorme importancia en la historia que estamos contando. La propuesta pestalozziana prestó fundamento y técnica en el preciso momento en que la escuela que conocemos adquiere su forma acabada y casi definitiva. Retomado herencias epistémicas y educativas como las de Locke y Comenio, ofreció un concepto clave para la instrucción. ${ }^{14} \mathrm{~A}$ partir de la idea de intuición el secreto de la instrucción descansaba en la apreciación sensible de los objetos o de sus formas vicarias dibujadas y presentadas a la percepción por la instruc- 
ción sistemática. Los objetos y las imágenes, como reemplazo pictórico de los objetos, cumplieron, así, un papel central en el desarrollo de las facultades mentales, porque representaban el origen auténtico, aunque no el proceso completo, de todo conocimiento verdadero.

\section{La persistencia del intuicionismo}

Mi actividad como maestro se guió por una pedagogía un tanto confusa. Defendía los principios del activismo, la importancia del grupo y la autogestión. Pero mis concepciones psicológicas y metódicas a la hora de la instrucción tenían muy poco fundamento. Me interesa recordar esto, porque falto de toda base psicológica o pedagógica al respecto armé, como cualquiera hace, una concepción práctica ad hoc. Si juzgo por los resultados, estaba en la línea de la didáctica tildada de "tradicional" por Aebli, a pesar de mi corazón renovador. Todavía puedo recordar perfectamente mis vanos intentos por hacer comprender a alumnos de 10 años los misterios de los números fraccionarios, recurriendo a estrategias de tiza de colores y dibujando chocolates y tortas divididas en porciones que se podían tomar o dejar. Exactamente las mismas, y sobre el mismo tema, que Aebli había descripto y demolido 20 años antes, dándolas como ejemplo del absurdo de la hipótesis intuitivista para el desarrollo de conceptos. ${ }^{15}$

El sensualismo ha persistido en las escuelas de muchas maneras. Esto no es extraño, porque 300 años de prédica no se desarraigarían tan rápidamente como los innovadores del siglo XX quisieron suponer. También, porque la enseñanza por los sentidos y la educación para el aprendizaje por los sentidos formaron, posiblemente, el más común sentido pedagógico en las prácticas escolares desde la consolidación de las escuelas. Un hecho que queda bien ilustrado, a mi entender, en este relato compilado por Larry Cuban, que describe el inicio de una clase en una escuela elemental en Boston en 1892.

"¿Con cuantos sentidos estudiamos geografía?"

"Con tres sentidos: vista, oido y tacto". Responden los estudiantes.

Se pide a los niños que busquen su mapa de Norteamérica y que comiencen con los cabos de la costa este (...). Cada niño coloca su dedo sobre "Cape Farewell" y cuando el maestro dice: "Comiencen", los alumnos dicen al 
Imágenes en la historia de la enseñanza: La lámina escolar

unísono, "Cape Farewell" y corren con su dedo hacia abajo en el mapa diciendo el nombre de cada cabo (...). Después de que los alumnos nombraron todos los cabos de la costa este de Norteamérica, empezando por el norte y terminando por el sur, se les pidió cerrar sus libros. Cuando los libros fueron cerrados, ellos corrieron sus dedos sobre la tapa y nombraron de memoria los cabos en orden de norte a sur.

“¿Cuántos sentidos estamos usando ahora?” Preguntó el maestro.

"Dos sentidos - tacto y audición -", responden los niños. (Cuban, 1993, p. 27)

Pero otra de las razones por las que el intuicionismo ha persistido, como perspectiva y como propuesta práctica hasta bien entrados los años 1960, es del orden de las ideas. Diversos autores como Aebli (1958), Bowen (1992), Not (1983), Obregón, Saldarriaga y Ospina (1997) señalan que influyentes pedagogos de la Escuela Nueva, tal es el caso de Decroly y Montessori, mantuvieron fuertes lazos conceptuales con el asociacionismo sensualista.

Por ejemplo, Louis Not diferencia los métodos de heteroestructuración y los de autoestructuración. Los primeros corresponden a los que se basan “(...) en la acción preponderante de un agente exterior y en la primacía del objeto estudiado”. Los segundos se basan "en la propia acción del alumno y en la primacía del sujeto" (Not, 1983, p. 18). Los métodos de autoestructuración, que reconocen los principios activos de la "educación nueva" no marcan de por sí una ruptura con la tradición de la enseñanza intuitiva. Esto se evidencia por el modo en que quedan ordenados en el eje: primacía de la observación/primacía de la experimentación. Decroly y Montessori se ubican en la primera parte y Claparéde y Dewey, en la segunda. La utilización de este eje permite marcar el corte con el intuicionismo y el fin de la legitimación teórica prestigiosa del papel de las imágenes como expresión vicaria de la realidad. Según Not, los métodos de descubrimiento mediante la observación que preconizaron Montessori y Decroly se sitúan en la prolongación de los métodos intuitivistas que “(...) conducen a lo que se ha podido llamar la enseñanza por el aspecto muy en boga en el siglo XIX". Y agrega: "Son los pragmatistas, entre ellos Dewey, los que marcan la ruptura esencial con el intuitivismo, partiendo de la acción como significación y producción de conocimiento" (Not, 1983, p. 140). 
Son dos los discursos que confluyeron en la crítica del intuicionismo. Una, se acaba de señalar, es el pragmatismo que, de la mano de Dewey, reemplaza la idea de intuición por la de actividad y proyecto para la resolución de problemas. La segunda es la llegada y el impacto de la psicogénesis piagetiana en los años 1950, que vuelve a debilitar el edificio intuicionista. ${ }^{16}$ Sin embargo, al menos en mi país, las prácticas escolares y de formación de maestros mantuvieron hasta entrados los años 1970 principios que no se apartan de las líneas fundamentales de la pedagogía dominante.

En Argentina, la persistencia de estas ideas puede registrarse en los manuales de didáctica utilizados para la formación de maestros. Estos marcan una coexistencia de diferentes líneas de pensamiento e interés en la formación de docentes de escuela básica. Esas líneas convivirán hasta el predominio de concepciones tributarias de la tecnología instruccional de origen norteamericano, logrado más tarde aunque no por largo tiempo. El reemplazo, en el año 1969, de las Escuelas Normales por Profesorados de nivel terciario para la formación de maestros, no solo modificó una forma organizativa. Marcó la finalización de un largo ciclo pedagógico que, entre otras notas, se caracterizó por la pregnancia del método y por la presencia de la línea pedagógica clásica. Los textos para maestros que dominarán con pocos años de diferencias mostrarán otros rasgos.

Pero todavía hasta inicios de los años 1970, muchos manuales conservaron una fuerte impronta de las bases intuicionistas. Desde los más sólidos teóricamente, hasta los dirigidos al mercado de las Escuelas Normales como resúmenes adaptados a los programas oficiales.

Por ejemplo en la Didáctica general de Calzetti se plantea que "Todos los procesos del espíritu - objetivación, generalización, abstracción, inducción, deducción - arrancan, en definitiva, de un hecho psicológico inicial: la intuición" (Calzetti, 1963, p. 129). Y se agrega, más adelante, que la enseñanza objetiva es una de las mayores exigencias de la pedagogía contemporánea. La didáctica, para Gärtner (1970, p. 111), debería reconocer en toda su amplitud el principio de visión y debe hacerlo no por razones teóricas, sino fundada en su experiencia práctica, y Stöcker (1964) sostiene en sus Principios de didáctica moderna que el principio intuición o visualización es aceptado como imprescindible de toda labor educativa y es el primero de los 
Imágenes en la historia de la enseñanza: La lámina escolar

cinco principios "universalmente reconocidos". ${ }^{17}$ Los Schmieder (1966, p. 75 y 76), a su vez, ofrecen cuatro consecuencias didácticas que surgen del principio de intuición: 1) cuidar que los objetos sean verdaderamente mirados; 2) contribuir a la formación de intuiciones claras por el recto tratamiento y utilización de los objetos; 3) partir siempre del medio circundante; 4) dibujar o modelar el objeto. ${ }^{18}$

Estos libros, utilizados en la formación docente, marcan una continuidad de concepciones intuicionistas, aunque combinadas en nuevas perspectivas. La vieja historia vuelve a tener actualidad. "Mas aunque el principio didáctico de intuición u objetivación se considera como uno de los más antiguos, su historia muestra que la concepción actual no ha sido igual desde el comienzo (...) solo queremos señalar que a través de ese desarrollo el problema de la visualización fue abordado una y otra vez, hasta el día de hoy, y siempre desde distintos ángulos. En este sentido, el principio de intuición resulta también un problema moderno a pesar de todo". (Stöcker, 1964, p. 40). Y como problema moderno pervive en las discusiones.

Por supuesto que existieron otras influencias. Pero aparecían divididas. Como alumno del magisterio leí Democracia y educación de Dewey. Pero Dewey se leía en pedagogía. Otros eran los didactas. En sus manuales, el principio de intuición continuaba vigente. El dispositivo escolar hizo el resto para marcar la permanencia de la lámina, la tiza de colores y el interrogatorio didáctico.

De las cosas a las imágenes fijas

La vigencia durante largo tiempo del intuicionismo se vio acompañada, en el nivel diario de las prácticas escolares, por un crecimiento progresivo del papel de las imágenes fijas, láminas escolares, dibujos y grabados en textos, que reemplazaron, muchas veces, los objetos de las lecciones de cosas. Debe haber quedado claro, a partir de la exposición anterior, que el uso de imágenes fijas en base a dibujos o esquemas jugaba un papel, pero no tenía el rol principal: la percepción directa de las cosas, en la medida de lo posible, ocupaba el centro del escenario cognoscitivo. Las imágenes fijas debían ser utilizadas cuando no fuera posible otra experiencia. En una versión moderna, ocupaban el séptimo de los nueve escalones del "cono de la 
experiencia” de Dale. ${ }^{19}$ ¿Por qué llegaron las láminas escolares a desplazar a los objetos? Argumentos de orden material y organizativo pueden encontrarse. Están en la propia

Describiendo la arquitectura de la clase, programas, tamaño de la clase, tarjetas de informes, reglas escritas, clasificación de maestros y prácticas de los supervisores en los años entreguerras, asumo que las condiciones de trabajo, las herramientas al alcance de los maestros y las explícitas expectativas de sus supervisores, describen un contexto organizacional que afecta lo que los docentes hacen diariamente (...) los arreglos organizacionales ayudan, y quizás en casos refuerzan, patrones de instrucción que prevalecieron en los salones de clase en la ciudad desde el inicio del siglo. Para los años 1930, el sistema escolar de Nueva York vio cambios en los programas que incorporaron el vocabulario progresista y sugirieron actividades para los maestros. Pero el tejido conectivo de la instrucción - arquitectura, tamaño de la clase, tarjetas de informes, reglas, procesos de evaluación y supervisión - establecieron el marco organizacional para las prácticas de enseñanza prevalentes. (Cuban, 1993, p. 61)

Las láminas se imponían por razones de economía, de practicidad y de mayor ajuste para el funcionamiento aceitado del mecanismo escolar. Es posible asumir la constancia de este "tejido conectivo" durante largos períodos. Por ejemplo, si se tiene en cuenta la configuración del espacio, creo que las salas de clase en mi niñez tenían muchos parecidos con las del principio del siglo. Más allá de la constante renovación pedagógica y de la prédica a favor del activismo ligado con el principio de intuición, esta dimensión estructural crea un marco para la interpretación de las derivaciones prácticas de esas teorías. Pero también concurren otros factores. Uno de ellos consiste en la simplificación de los planteos originales. Estos procesos de traducción y simplificación de las pedagogías en situación escolar son conocidos y no debo detenerme aquí en ellos. Baste decir que estas simplificaciones convierten en preceptivos enunciados teóricos, eliminan los aspectos más complejos de las hipótesis y enfatizan, si se permite la expresión, los aspectos visibles y conductuales de las propuestas. Por supuesto que ninguna de estas transformaciones es ajena al "tejido conectivo de la instrucción". Pero no dejan de tener una dinámica propia. Estas transformaciones, como ya se señaló, ocurren tempranamente con la difusión escolar de las ideas de la pedagogía sensualista. 
Imágenes en la historia de la enseñanza: La lámina escolar

También juega, seguramente, el problema de la simplificación de la realidad para facilitar la actividad escolar. En el caso que nos ocupa, la percepción del mundo debía apuntar al conocimiento de la verdad objetiva. La organización de la información tenía que ayudar a ese objetivo, más si la mente de los que conocen, los niños, todavía no está completamente organizada o, como se creía, era pasible de representaciones "confusas". Es posible asumir que, para ayudar en este proceso de clarificación, puede ser un recurso importante recurrir a lo que Eisner (1998) denomina una sintaxis de reglas más que una figurativa. ${ }^{20}$ Esta sintaxis de la forma de representación tiende a codificar la realidad de un modo más claro y simplificado, resaltando los rasgos que se prestarán a la percepción y ordenándolos en un artificio práctico y apto para los usos escolares. Las sintaxis de reglas son más expresables cuando el objeto puede ser controlado y codificado. El camino hacia la esquematización de las lecciones de cosas, ejemplificado en la edición de interrogatorios modelo fijos para conducir la observación de los objetos expresa este proceso de codificación..$^{21} \mathrm{La}$ lámina escolar podía cumplir esas funciones de un modo más acabado y sencillo que el contacto directo con la realidad. Probablemente por eso, adquirió jerarquía más allá del precepto originario. En el marco disciplinado, orgánico y evaluador de las escuelas, las imágenes fijas ofrecían más que una imagen vicaria. Creaban un mundo adecuado a las necesidades y posibilidades del sistema de enseñanza masivo.

El resultado de este dezplazamiento hacia las láminas y las ilustraciones fue lo que conocí en mi escolaridad. Pero, en pocos años, el uso de láminas e ilustraciones comenzó a cambiar de sentido.

Las imágenes permanecieron implicadas en la sala de clase. Pero, mayormente, como apoyo informativo, "testimonio" de la tarea o indicador de normas o eventos. No era esa la jerarquía que tuvieron durante tres siglos. Su misión era diferente. Ya sin una teoría que las avale, permanecen como un medio auxiliar para proveer datos del mundo a estudiar o cooperar en la organización de la clase. La imagen gráfica, tal como se la utiliza mayormente, no sería ya "el objeto" que provocaría la representación en el espíritu o la mente - cuando las condiciones no permitieran o aconsejaran el contacto directo. La imagen, ahora, funge como un texto para brindar información, apoyar información de otro tipo u organizar información. ${ }^{22}$ 
Me pregunté por la importancia adquirida por las imágenes fijas en las salas de clase. Algunas de las razones propuestas consistieron en los procesos de reducción de la teoría, en la estructura del dispositivo escolar y en la simplificación para la organización y secuencia de la enseñanza. También se señaló la existencia de un progresivo cambio en las funciones de las imágenes fijas en la sala de clase, hacia roles de motivación o apoyo informativo. Esto parece implicar un cambio radical en su utilización y, en mi opinión, marca finalización de un modo de presentar/representar el mundo. Quisiera ahora avanzar, y concluir, con esa consideración.

\section{¿El fin de un modo de presentar/representar?}

El uso de las láminas, los modelos, las ilustraciones en los textos, los mapas, ya no es lo que era. Cambió, desde ya, la arquitectura de las salas de aula. También la iconografía que las poblaba. Múltiples soportes informativos han ingresado a las escuelas - matizado por el sector social y económico de sus públicos - y disminuyó la producción propiamente escolar de imágenes. Fotografías, películas, la multiplicación de libros disponibles y los medios gráficos de masas tuvieron mucho que ver en esto. Quisiera plantear algunas sugerencias sobre factores que influyeron en este proceso que cambió, de manera importante, la configuración de las salas de aula y la estructura sistemática de la instrucción.

Un factor de mucha importancia es la quiebra del fundamento psicológico empirista de la didáctica tradicional. Pese a la continuidad teórica del intuicionismo, el panorama cambió profundamente en las últimas décadas. Las psicologías operatorias trasladan el foco de la representación del mundo por la imagen y lo colocan en la acción sobre los objetos. La acción prima sobre la observación. Este ataque debilita el fundamento del uso de imágenes. No como recurso didáctico, sino como vía regia del conocimiento. Lo que se cuestiona es el argumento epistémico en el que se sostiene la enseñanza intuitiva.

Otro factor, que adquiere relevancia en Argentina, es el paso que se produce en el currículum hacia los años 1970, desde un orden moral patriótico hacia un orden universal y científico. ${ }^{23} \mathrm{En} \mathrm{mi}$ opinión, este movimiento tiene repercusiones en la utilización de imágenes en la enseñanza. 
Imágenes en la historia de la enseñanza: La lámina escolar

Las láminas representaban un mundo ordenado según patrones claros relacionadas con la moralidad, la practicidad y la patria. Los currícula hasta 1960, con su disposición tópica del conocimiento, el énfasis en el espacio y el papel del ejemplar, se concretaban perfectamente en láminas e ilustraciones. Las láminas no solo representaban la realidad vicariamente para la aprehensión sensible del mundo "cuando este no puede observarse de manera directa". Las láminas imponían un orden coincidente con el patrón del currículum. El propio currículum estaba pleno de "imágenes" que las nuevas tendencias a la ciencia y los procesos tienden a borrar. El currículum era, hasta ese momento, un currículum que se podía "ver", escribir y contar. Cuando este orden comienza a cambiar y llega a su punto de ruptura hacia los años 1970, las láminas comienzan a perder su lugar y a modificar su función. También es cierto que enfrentan más dificultades como soporte. No porque la escuela se haya vuelto activa y se haya volcado a la experiencia directa. Si no, simplemente, porque los procesos, las funciones y las estructuras que pueblan los nuevos currícula no son representables como los lugares, los hechos y los seres. En nuestras maneras de pensar el currículum y el contenido educativo, la naturaleza y las "cosas" fueron reemplazadas por los procesos y las estrucutras de las disciplinas. Las disciplinas son sistemas complejos y formalizados de conocimiento. Sus "objetos" son principios, leyes y conceptos que, en verdad, no son tan pasibles de ser representados figurativamente.

Como tercer factor se debe señalar que las imágenes fijas tenían la ventaja práctica de ordenar y simplificar el mundo "allí afuera". La imagen representa una simplificación y un ordenamiento de lo que representa. Esa simplificación cumplía con propósitos moralizantes, pero también cognitivos, porque simplifica el proceso de atención y lo focaliza. Elimina la peligrosa proliferación de información de los hechos reales. Los ejemplares son perfectos, los rasgos claros, la atención no es distraída y, más aún, es dirigida. El interrogatorio sistemático es posible y facilitado. Imágenes e interrogatorio están indisolublemente unidos en la perspectiva metódica de las escuelas. Las láminas fueron algo así como una expresión didáctica del dictum del currículum: el orden sencillo y común de la enseñanza en las escuelas básicas. En las perspectivas metódicas que dominaron hasta los años 1970, el esfuerzo de los alumnos debía ser dirigido en secuen- 
cias estables y la actividad escolar no admitía cualquier tipo de experiencia. El uso de imágenes fijas estuvo ligado a pedagogías de método formal. Se debilitó, por supuesto, junto con estas pretensiones que hoy pocos reconocen. ${ }^{24}$

Por otra parte, con la aparición del "niño científico" el nuevo principio de regulación reside en la actividad exploratoria. Las imágenes cambian de soporte y de función y la producción de imágenes como actividad es, a veces, la traducción escolar disminuida de la actividad exploratoria. También en la escuela aparecen nuevas formas discursivas: enciclopedias, libros, revistas y periódicos pasan a jugar un lugar importante y portan nuevas imágenes de un tipo y un valor muy diferente al que caracterizó las láminas escolares. La lámina escolar, que podría calificarse como "realidad recontextualizada", se diluye con el ingreso de "la realidad" y "el conocimiento" vía soportes no escolarizados inicialmente (fotos, películas, programas de computadora).

Por último, puede decirse que, por varias vías, hoy vuelven a tener importancia pedagogías "de la palabra". La reflexión en torno al papel de las imágenes y de las representaciones en la didáctica debe mantener siempre en mente lo siguiente: la pedagogía mantuvo una discusión de tres siglos contra al enseñanza verbalista y memorista. Como señalaba Stöker (1964), el principio de la intuición se opone a la escuela de "la palabra" y "el libro". Actualmente, no se abandona la cuestión de la representación, por el contrario, pero el nuevo escenario lo demarcan la acción y, sobre todo, el papel del lenguaje. Esto abre interesantes problemas porque, como marcaba Stöker (1964, p. 42), "cosa y palabra son un campo de tensión en la enseñanza". En esta tensión se inscriben las viscitudes de la utilización de imágenes en la enseñanza.

En resumen, quisiera sugerir que el uso de imágenes fijas figurativas jugó roles en distintas intersecciones y no puede ser analizado solo desde las fundamentaciones sostenidas sobre el proceso de aprendizaje o de formación de la experiencia. La pregunta que traté de comenzar a delinear es: ¿Parte de qué historia son las imágenes como forma de enseñanza y cual es la narración en la que desaparecen en su forma y su función original?

Tal vez, la certeza pestalozziana tenía algún sentido. Empecé este relato con imágenes evocadas, con una representación de la esco- 
Imágenes en la historia de la enseñanza: La lámina escolar

\section{laridad en mi tiempo de alumno y de maestro. Solo mirando reflexi- vamente las "cosas", analizando sus partes, comienza a intuirse el hilo que las unía. Quizás ahora pueda empezar a comprender.}

\section{Recebido e aprovado em fevereiro de 2004.}

\section{Notas}

1. Ver, por ejemplo, "Dos modalidades de pensamiento" y "El lenguaje de la educación”, en Bruner (1988).

2. Así se planteaba en la Ley 1420 de Educación Común y Obligatoria de la República Argentina: "Artículo 1. Las escuelas primarias tienen por objeto favorecer y dirigir simultáneamente el dsarrollo moral, intelectual y físico de los niños que están en edad escolar".

3. La vigencia de estos principios, que estructuran el desarrollo de la escolaridad moderna, es argumentada por Obregón, Saldarriaga y Ospina (1997, volumen 1, p. 14 y 15).

4. ¿Por qué, pues, ha de darse comienzo a la enseñanza por la narración verbal y no mediante la inspección de la cosa? Después, una vez presentada la cosa, venga la narración para explicar más profundamente lo expuesto" (Comenio, 1996, p. 124).

5. Existe una edición que incluye la versión en español de los textos: Joh. Amos Comenii, Orbis Sensualium Pictus, México, DF: Edit. Porrúa, 1993.

6. Pestalozzi (1936, p. 203) relata que una mujer del pueblo colocó para su niño un pájaro pintado " $y$ de ese modo indica el punto preciso en que debía comenzar el arte a dar al niño una firme y clara conciencia de los objetos de la naturaleza”. “(...) cuan fácilmente podría el arte colocar en el niño, mediante tales representaciones sensibles, un fundamento general para la intuición sensible de todos los objetos de la naturaleza y del arte”.

7. “PPuedan los hombres comprender que el fin de toda instrucción nada otra cosa es y nada puede ser eternamente que el desenvolvimiento de las capacidades y la precisión de los conceptos (...)" (Pestalozzi, 1936, p. 216).

8. Dice Pestalozzi: "El mecanismo de la naturaleza humana sensible está sometido en su ser a las mismas leyes por las cuales desarrolla sus fuerzas la naturaleza física. Conforme a estas leyes, toda instrucción debe grabar de un modo invariablemente profundo en lo íntimo del ser humano lo esencial de la materia de su conocimiento (...)". "Traté de descubrir las leyes a que, conforme a su naturaleza misma, ha de someterse el desarrollo del espíritu humano; sabía que tenían que ser las mismas de la naturaleza físico sensible y creía encontrar seguramente en ellas el hilo con el que se pudiera urdir la trama de un método de instrucción psicológico" (Pestalozzi, 1936, p. 110 y 111).

9. Sin embargo el fundamento pestalozziano de la unidad entre las leyes de la naturaleza y las de la instrucción encuentra ecos hasta mucho después. Por ejemplo, puede leerse en el Programa para las Escuelas Primarias de la Provincia de Córdoba de 1943: "Por ello estos programas no solo sugieren, sino que en cierta medida imponen que el conocimiento no debe ser trasmitido y asimilado fríamente, a la clásica manera dosificada de la escuela preterizada, sino fortificado y hondamente sentido por un proceso de enlace y coordinación 
y vitalizado en el seno de la Naturaleza, fuente insustituible de verdad, y de belleza y de sugestiones que influirán en el desarrollo ulterior del educando, despertando aptitudes y vocaciones a la par que perfeccionarán su mundo moral".

10. Por ejemplo estas eran las instrucciones en los Programas Sintéticos e Instrucciones Didácticas para las escuelas primarias de la provincia de Córdoba de 1916: "Cada cosa se observará siempre que sea posible en sus propios medios, apelando a los objetos de museo y a las ilustraciones impresas solo en defecto de las mismas". Algunos años antes, el Reglamento General para las Escuelas Comunes de la Provincia de Buenos Aires de 1876 establecía que uno de los métodos que se emplearán en la enseñanza sería el intuitivo "haciendo uso de objetos siempre que sea posible (..)".

11. En el Reglamento General para las Escuelas Comunes de la Provincia de Buenos Aires de 1876 se prescribía que: "Los métodos que se emplearán con preferencia en la enseñanza serán: $1^{\circ} \mathrm{El}$ intuitivo (...); $2^{\circ} \mathrm{El}$ sinóptico o fundamental; $3^{\circ} \mathrm{El}$ filosófico o sea el analítico, alternado con el sintético, empleados ambos oportunamente".

12. Cabe a esta altura una aclaración importante. Estoy aceptando, en los hechos, una línea marcada por Comenio, Pestalozzi y los discípulos de Herbart. Dejo intencionadamente de lado la influencia froebeliana. Esta selección no tiene ninguna justificación desde una historia de la pedagogía o de la didáctica. Solo se explica porque, dentro de los límites del trabajo, se procuró enfatizar lo que puede ser la línea principal que contextualiza el uso de las imágenes en la instrucción. En Froebel, el juego y la implicación activa con el entorno constituían un contenido principal de la enseñanza. El énfasis en la actividad y el carácter orgánico de la instrucción planteaban un escenario diferente para la actuación en el aula y la dirección de la instrucción que el que resultó dibujado por la línea de la pedagogía "clásica".

13. El Proyecto de Plan de Estudios y Programas para las Escuelas de Nuevo Tipo, debatido en 1930 en el Consejo Nacional de Educación de la República Argentina, planteaba: "Con ese criterio no se enseñará aisladamente Botánica, Zoología, ni Mineralogía; se relacionará entre sí y con la Geografía, el dibujo, el trabajo manual y la obra humana. El profesor Sadler señala la inconveniencia de la multiplicación de las disciplinas, pues con ella sólo se consigue desconcertar al alumno obligándolo a variar a cada momento su 'foco mental', y Cousinet también lo hace notar: 'La separación rigurosa de materias impide ver el lazo real que las une; impide fijar la atención del niño que es tan móvil y trabajar su espíritu porque esa atención y ese trabajo son interrumpidos por el paso a otro estudio'. Decroly no reclama con menos insistencia esa correlación: 'La personalidad del niño, dice, es un todo y la actividad mental es un todo también y sus modos de adquirir y reaccionar forman un todo; la diferenciación de las actividades que se reparten la jornada escolar es pues arbitraria; para el niño de la escuela primaria al menos, todo está en todo y es necesario esforzarse más en relacionar que en separar, más en fusionar que en levantar compartimentos" (El monitor de la educación común, 1930, p. 188).

Sobre la inclusión de unidades globalizadas puede verse, por ejemplo para el caso de Colombia, el trabajo de Obregón, Saldarriaga y Ospina, 1997. En el volumen 1, Capítulo 6, el apartado "acercamiento a lo global", y en el volumen 2, Capítulo 12. Con relación a Argentina, puede verse Palamidessi y Feldman (1999).

14. Así lo marcan taxativamente Obregón, Saldarriaga y Ospina, 1997, p. 331: "A riesgo de pasar por anacrónicos, podemos ilustrar el alcance del término intuición para este período, diciendo que fue lo que es hoy, para quien hable de pedagogía, la frase construcción de conocimiento".

Educ. Soc., Campinas, vol. 25, n. 86, p. 75-101, abril 2004

Disponível em <http://www.cedes.unicamp.br> 
Imágenes en la historia de la enseñanza: La lámina escolar

15. La crítica específica sobre la enseñanza de los números fraccionarios y el cálculo de superficies puede verse en Aebli, 1958, en páginas15 a 22.

16. Es necesario aclarar que para Aebli la ruptura real con el intuitivismo no puede ubicarse en el pragmatismo. Acusa a Dewey, junto con Claparéde, de que “(...) en la interpretación de la naturaleza intrínseca del pensamiento se mantuvieron tributarios de la psicología asociacionista" (1958, p. 26). El autor considera que será solamente con la llegada de la psicología de Piaget que se produce el corte definitivo con el asociacionismo sensualista.

17. Los otros cuatro son los de actividad del alumno, realismo, consolidación del éxito y adecuación al niño (ver Stöcker, 1964, p. 38). Los cinco principios reunidos muestran la síntesis entre distintas corrientes que se fueron desarrollando en el transcurso de la escolaridad de masas. También muestran la capacidad de pervivencia del intuicionismo dentro de las pedagogías activas o nuevas. Probablemente porque sus fundamentos filosóficos no guardaran una diferencia tan notable.

18. El libro de los Schmieder es la octava edición de 1966. No hay mención de la edición original. Puede pensarse que fue escrita a principios de los años 1950. En el caso del manuel de Calzetti, esta era la vigesimoquinta edición de la obra publicada, por primera vez, en 1939. Notable persistencia! Los otros libros fueron publicados con poca diferencia de sus ediciones originales.

19. El cono de la experiencia de Dale es un recordado instrumento conceptual utilizado en la formación de profesores de educación básica durante los años 1970 y 1980. Expresaba las distintas formas de aprehender los fenómenos. Comenzaba en la experiencia directa y pasaba sucesivamente a: experiencia simulada, dramatizaciones, demostraciones, visitas y excursiones, Exposiciones, filmes y televisión, Imágenes fijas, radios, grabaciones, símbolos visuales, símbolos orales. Una descripción puede verse en Zabalza, 1997, p. 204.

20. Para Eisner, las formas de representación son formas ordenadas y llama "sintaxis" a su ordenamiento. Las formas individuales de representación pueden ordenarse sobre un continuo. En un extremo están aquellas que se deben organizar según un conjunto de reglas públicamente codificadas. En el otro extremo priman las formas de representación cuyas reglas no tienen carácter prescriptivo y en las que se premia la novedad productiva y la posibilidad de interpretación. "Mientras menos gobernada por reglas y más figurativa es la sintaxis, más permite una interpretación personal y una forma novedosa" (Eisner, 1998, p. 88). Las sintaxis figurativas ofrecen un marco de ambigüedad que genera ventajas cognitivas sobre todo en perspectivas educativas que aceptan las perspectivas múltiples, el juicio, la especulación y la interpretación.

21. Por ejemplo, el siguiente diálogo modelizaba una observación sobre "El trigo":

"- ¿Qué es esto?

- Una espiga de trigo

- ¿Qué encierra esta espiga?

- Granos de trigo.

- Granos de trigo como estos ¿para qué sirve el trigo?

- Para hacer pan

- ¿Es con los granos de trigo que se hace el pan?

- Es con la harina (...)".

En El monitor de la educación común, XIX, 1903, p. 299. 
Daniel Feldman

22. Por supuesto que hay otras maneras de entender el papel de las representaciones. Claro que operan, en general, en propuestas sofisticadas que no tienen demasiado eco en las escuelas. Por dar un ejemplo, la teoría de J. Bruner sobre los sistemas de representación desarrollada hace ya bastante tiempo (Bruner, 1969) pero, todavía, de mucha circulación. Claro que los sistemas que Bruner propone no son "imágenes". Los sistemas de representación son principios de codificación y procesamiento de información. Igualmente, no creo que esos sistemas excluyan la idea de representación como imagen, aunque solo uno de ellos se caracteriza por la iconicidad de la representación. Más aún, se requiere de la variedad y abundancia de imágenes de acciones, tareas y objetos a los que recurrir como apoyo en los procesos de conceptualización cada vez más abstractos y generales. Siempre se puede empezar “(...) con una explicación 'intuitiva' que esté al alcance del estudiante (...)” (Bruner, 1997, p. 138) en el tránsito entre formas de representación que caracteriza la espiral bruneriana.

23. Sobre este proceso en Argentina puede verse Palamidessi (2001).

24. Salvando el trabajo de Aebli (1995) en 12 formas básicas de enseñar. Según mi conocimiento, una solitaria y muy interesante reivindicación del formalismo en didáctica.

\section{Referencias bibliográficas}

AEBLI, H. Una didáctica fundada en la psicología de Jean Piaget. Buenos Aires: Kapeluz, 1958.

AEBLI, H. 12 formas básicas de enseñar. Madrid: Narcea, 1995.

BOWEN, J. Historia de la educación occidental. Barcelona: Herder, 1992. t.3 El Occidente moderno.

BRUNER, J. Notas hacia una teoría de la instrucción. México: UTEHA, 1969.

BRUNER, J. Realidad mental y mundos posibles. Barcelon: Gedisa, 1988.

BRUNER, J. La educación puerta de la cultura. Madrid: Visor, 1997.

CALZETTI, H. Didáctica general. Buenos Aires: Estrada, 1963.

COMENII, J.A. Orbis Sensualium Pictus. México, DF: Porrúa, 1993.

COMENIO, J.A. Didáctica magna: en páginas escogidas. Buenos Aires: AZ; UNESCO, 1996. (Publicada originalmente en Opera Didactica Omnia, Amsterdam, 1657.)

CONSEJO GENERAL DE EDUCACIÓN (Argentina). Programa para las escuelas primarias de la Provincia de Córdoba, 1943. 
Imágenes en la historia de la enseñanza: La lámina escolar

CONSEJO GENERAL DE EDUCACIÓN (Argentina). Reglamento general para las escuelas comunes de la Provincia de Buenos Aires. Digesto 1875-1888, Provincia de Buenos Aires, 1876.

CONSEJO NACIONAL DE EDUCACIÓN (Argentina). Plan de estudios para las escuelas comunes. El Monitor de la Educación Común, Buenos Aires, n. 129, 1888.

CUBAN, L. How teachers taught. New York: Teachers College, 1993.

DIRECCIÓN GENERAL DE ESCUELAS. Programas sintéticos e instrucciones didácticas para las escuelas primarias de la Provincia de Córdoba. Boletín Oficial, 1916.

EGGEN, P.; KAUCHAK, D. Estrategias docentes. Buenos Aires: Fondo de Cultura Económica, 2000.

EISNER, E. Cognición y curriculum: una visión nueva. Buenos Aires: Amorrortu, 1998.

GÄRTNER, F. Planeamiento y conducción de la enseñanza. Madrid: Kapeluz, 1970.

JOYCE, B.; WEIL, M.; CALHOUN, E. Modelos de enseñanza. Barcelona: Gedisa, 2002.

MCEWAN, H.; EGAN, K. La narrativa en la enseñanza, el aprendizaje y la investigación. Buenos Aires: Amorrortu, 1998.

NOT, L. Las pedagogías del conocimiento. México, DF: Fondo de Cultura Económica, 1983.

OBREGÓN, J.; SALDARRIAGA, O.; OSPINA, A. Mirar la infancia: pedagogía, moral y modernidad en Colombia, 19031946. Medellín: Colciencias; Foro Nacional de Colombia, 1997.

PALAMIDESSI, M.; FELDMAN, D. Principios clasificatorios en los planes de estudio para la educación primaria argentina. Trabalho apresentado na $11^{\text {a }}$. Jornadas de Historia de la Educación., Universidad Nacional de Quilmes, set. 1999.

PALAMIDESSI, M. A ordem e o detalhe das coisas ensináveis: uma leitura dos planos, programas e currículos para a escola primária. 2001. 
Tese (Doutorado) - FACED, Universidade Federal do Rio Grande do Sul, Porto Alegre.

PESTALOZZI, G.E. Cómo enseña Gertrudis a sus hijos. Madrid: Espasa Calpe, 1936.

SCHMIEDER, A.; SCHMIEDER, J. Didáctica general. Buenos Aires: Losada, 1966.

STÖCKER, K. Principios de didáctica moderna. Buenos Aires: Kapeluz, 1964.

ZABALZA, M. Diseño y desarrollo curricular. Madrid: Narcea, 1997. 